\title{
ASSISTED DELIVERY METHOD IN MANAGING PARTIAL PRIMARY UTERINE INERTIA IN A GERMAN SHEPHERD BITCH
}

\author{
N. AHMED ${ }^{*}$, M. SHARMA ${ }^{2}$, S. N. YADAV ${ }^{3}$, B. K. SARMA ${ }^{2}$, R. DEVI ${ }^{2}$, \\ P. THAKURIA ${ }^{3}$ AND A. J. NATH ${ }^{4}$
}

${ }^{1}$ Department of Animal Reproduction, Gynaecology and Obstetrics, Lakhimpur College of Veterinary Science, Assam Agricultural University, Joyhing - 787 051, North Lakhimpur, Assam, India ${ }^{2}$ Department of Veterinary Surgery and Radiology, Lakhimpur College of Veterinary Science, Assam Agricultural University, Joyhing - 787 051, North Lakhimpur, Assam, India

${ }^{3}$ Department of Veterinary Medicine, Lakhimpur College of Veterinary Science, Assam Agricultural University, Joyhing - 787 051, North Lakhimpur, Assam, India

${ }^{4}$ Department of Veterinary Microbiology, Lakhimpur College of Veterinary Science, Assam Agricultural University, Joyhing - 787 051, North Lakhimpur, Assam, India

\begin{abstract}
This communication represents a successful management of partial primary uterine inertia in a 2 years old German Shepherd bitch, presented with the complaint of difficulty in parturition at term. The bitch was subjected to assisted delivery method with the parental use of dextrose, oxytocin and calcium; and manual application of whelping forceps. A live healthy female pup was delivered and the bitch came to normal physiological health within one week.
\end{abstract}

Key words: Assisted delivery, Bitch, German Shepherd, Uterine inertia

\section{INTRODUCTION}

Dystocia is the condition characterized by marked prolongation of the first or especially second stages of parturition and becomes difficult or impossible for the dam to deliver the fetus/fetuses without any artificial aids (Roberts, 2004). Dystocia is an important emergency condition in animals and its negligence may lead to life threatening condition for both dam and fetuses (Ahmed et al., 2017; Ahmed et al., 2019). The causes of dystocia may be of fetal or maternal origin. However, primary uterine inertia is a common reason of maternal cause of dystocia in bitches and is characterized by occurrence of weaker and less frequent or shorter than normal uterine contraction resulting in the course of labour, thereby causing difficulty in parturition (Darvelid and Linde-Forsberg, 1994; Noakes et al., 2018). Primary uterine inertia has been further classified as complete or partial (van der Weijden and Taverne, 1994). Complete primary uterine inertia signifies fail to initiate the second stage of labour and no puppies are delivered. However, partial primary uterine inertia is defined as initiation of normal labour but failure to deliver all 
Indian Journal of Animal Health, December, 2020

Assisted delivery in managing uterine inertia

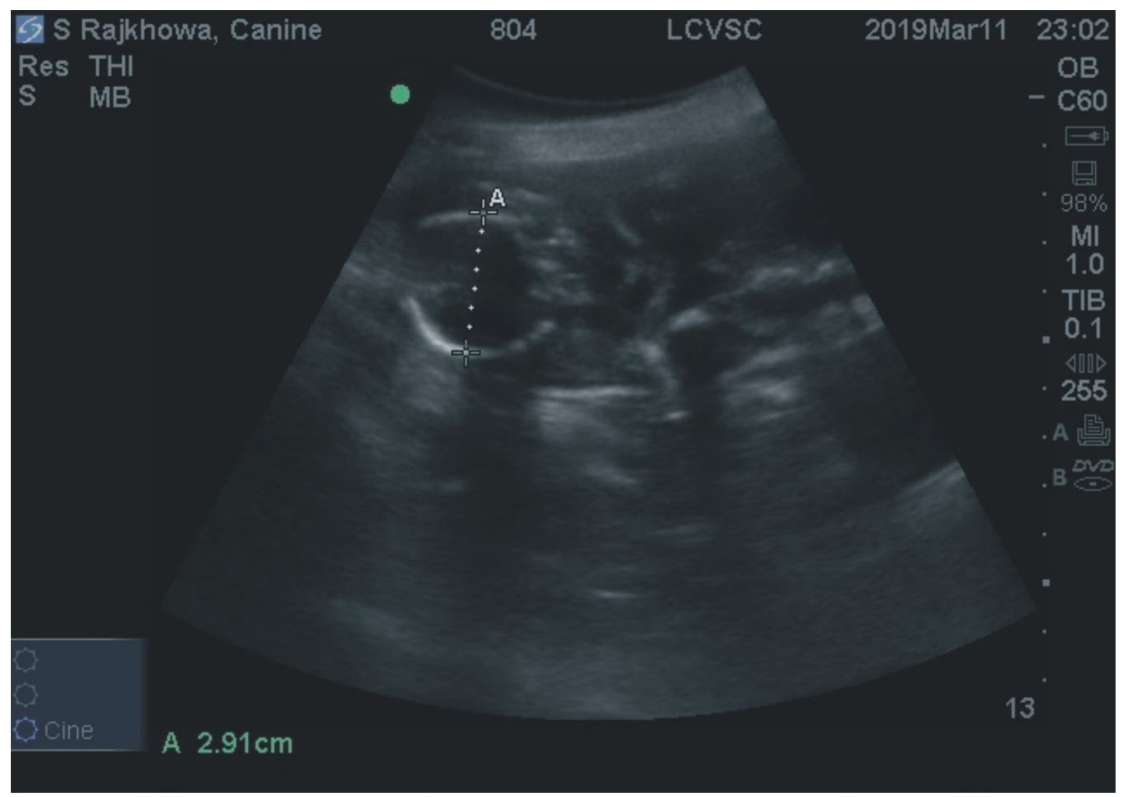

Fig. 1. Photograph showing ultrasonographic image of fetal head (diameter $2.91 \mathrm{~cm}$ )

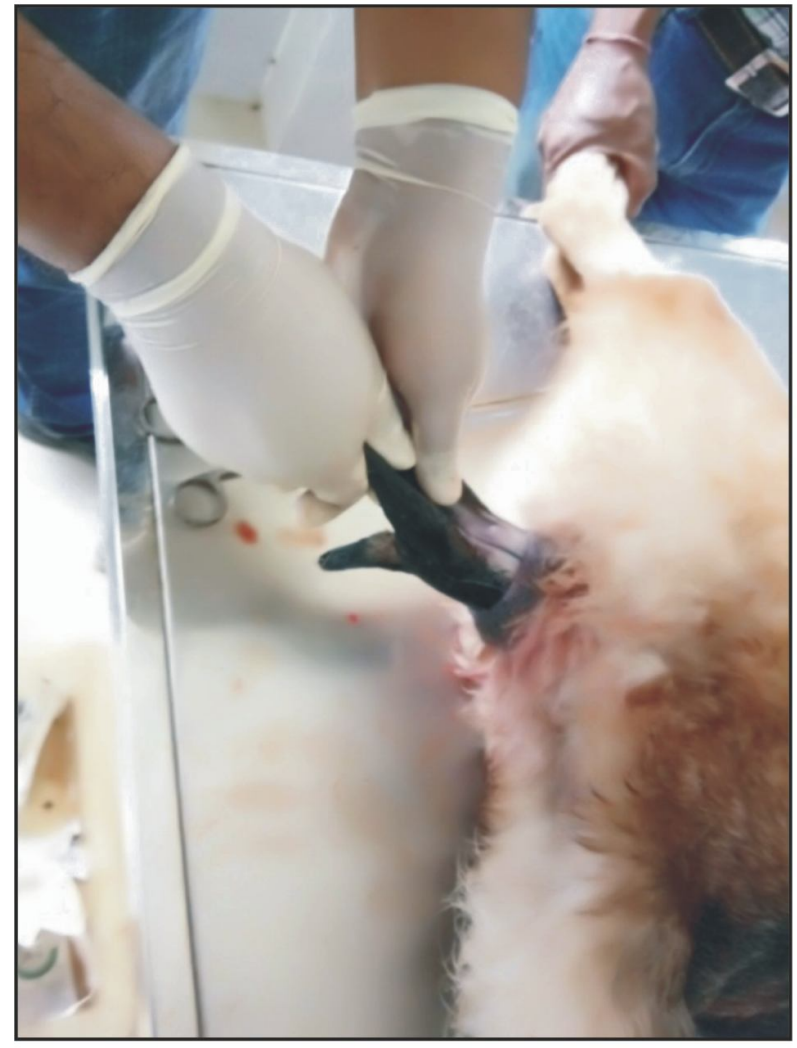

Fig. 2. Photograph showing manual removal of the fetus

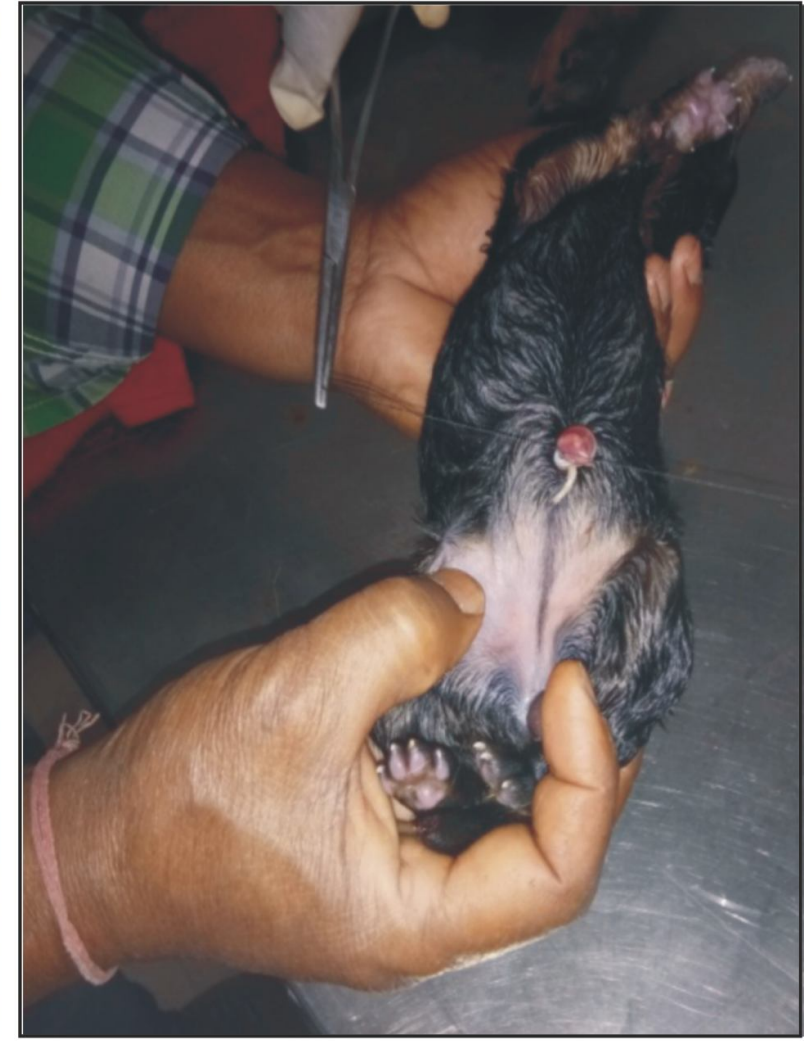

Fig. 3. Photograph showing neonatal management of delivered fetus 
puppies (Gendler et al., 2007). This paper represents a successful therapeutic management of partial primary uterine inertia in a German Shepherd bitch.

A 2 years old German Shepherd bitch (body weight $28 \mathrm{~kg}$ ) having 65 days of pregnancy was presented in the Veterinary Clinical Complex, Lakhimpur College of Veterinary Science, Assam Agricultural University, Joyhing, Lakhimpur, Assam, India with the history of straining as well as the attempt of whelping since last 8 hours. The bitch was dull, depressed and anorectic. Details clinical examination revealed that rectal temperature, heart rate and respiration rate were $101.5^{\circ} \mathrm{F}$, 90 beats per minute and 20 breaths per minute respectively. On clinico-gynaecological examination, the cervix was found open, however, the fetus was beyond reach of the operator and physical status of the fetus could not be assessed. The Radiographic evaluation revealed presence of single fetus with full skeletal development. Ultrasonography was performed to evaluate the fetal viability by monitoring heart beats and movements and it was confirmed the presence of a live fetus with full term age (Fig. 1). Hence, the case was diagnosed as partial primary uterine inertia and it was decided to attempt with assisted delivery method with the use of both parental medication and whelping forceps.

The bitch was treated with 5\% dextrose normal saline (Jedux Parenteral Pvt. Ltd.) @ $350 \mathrm{mg} /$ kg b. wt. i.v., oxytocin@ 20 IU or 4 mL i.v. (Oxytocin; Hindustan Medicines Pvt. Ltd.) and calcium injection@ $0.1 \mathrm{~mL} / \mathrm{kg}$ b. wt. i.m. (Cal-BD; Vetsfarma Ltd.). After 20 minutes of treatment, the vaginal discharge was noticed. After one hour of treatment, the bitch was examined per vaginally and tip of the fetal tail could be palpated per finger. Hence, it was decided to manage the condition with whelping forceps. The position of the presented fetus was fixed by gripping it through the abdominal wall of the bitch. The closed whelping forceps was introduced into the uterus. Then the jaws of the parturition forceps were opened as widely as possible and again depressed downwards to grasp the whole width of the fetal pelvis as the presented fetus was in posterior presentation. With steady and gentle tractions, the live female pup was delivered (Fig. 2). Immediately, the pup was wiped with a clean dry towel and then umbilical cord was cut and tied with black braided silk material (Fig. 3). Then tincture iodine was applied to prevent infection. The time required for expulsion of placenta was 7 minutes after assisted delivery of the pup. The bitch started eating from the same day evening and came to normal physiological health within one week.

Primary uterine inertia is an important maternal cause of dystocia in bitches and might be caused by anatomical abnormalities or disturbances of the physiological interaction between hormones and electrolytes (Bergström, 2009). In the present case, the bitch had delivered single pup which might be the cause of primary uterine inertia as early researchers had opined that primary uterine inertia could be developed because of litter size: either too small litter or myometrium is overstretched secondary to a large litter size (Gendler et al., 2007).

Many researchers reported that hypoglycaemia as another cause of uterine inertia in bitches (Jones and Joshua, 1988; Chethana et al., 2018 ). As the bitch was reported to be anorectic since the initiation of labour so the bitch might be hypoglycaemic (Fernandez et al., 2009). Oxytocin treatment helped in initiation and maintenance of uterine contraction to facilitate whelping process (Talukdar et al., 2016). Calcium, the most important electrolyte regulated myometrial contractions and 
application of calcium during uterine inertia enhanced contraction of uterine muscle (Babu et al., 2014).

In conclusion, partial primary uterine inertia in a German Shepherd bitch could successfully be treated by the strategic application of dextrose, oxytocin and calcium along with manual use of whelping forceps, where diagnostic imaging aids play a vital role to

\section{REFERENCES}

Ahmed N, Baishya MP, Das JM, Das A, Boro PKet al., 2019. Surgical management of dystocia in an Assam Hill goat : A case report. Haryana Vet, 58(S.I.): $114-115$

Ahmed N, Bayan H, Vanlalhriatpuia, Ahmed FA and Lalrintluanga K, 2017. Surgical management of dystocia in a pug bitch. North-East Vet, 16(4): $33-34$

Babu GR, Srilatha B and Venkata G, 2014. Management of complete uterine inertia in a bitch. Intas Polivet, 15(02): 308-309

Bergström A, 2009. Dystocia in the bitch: epidemiology, aetiology and treatment. Doctoral thesis submitted to Swedish University of Agricultural Sciences, Uppsala

Chethana DH, Krishnaswamy A and Sudha G, 2018. Comparative studies on uterine tocodynamometry in cases of primary complete uterine inertia and spontaneous whelping dogs. Int J Livest Res, 8(2): 162-166, doi: 10.5455/ ijlr.20170718053114

Darvelid AW and Linde-Forsberg C, 1994. Dystocia in the bitch: A retrospective study of 182 cases. J Small Anim Pract, 35(8): 402-407, doi: 10.1111/j.1748-5827.1994.tb03863.x overcome the situation.

\section{ACKNOWLEDGEMENTS}

The authors are grateful to the Dr. U. R. Tamuli, Associate Dean, Lakhimpur College of Veterinary Science, Assam Agricultural University, Lakhimpur, Assam, India.

Conflict of interest: The authors declare that they have no competing interests.

Fernandez NJ, Barton J and Spotswood T, 2009. Hypoglycemia in a dog. Can Vet J, 50(4): 423426

Gendler A, Brourman JD and Graf KE, 2007. Canine dystocia: medical and surgical management. Comp Cont Educ Pract, 29(9): 551-563

Jones DE and Joshua JO, 1988. Reproductive Clinical Problems in the Dog, $2^{\text {nd }}$ edn., Wright, London, pp80-112

Noakes DE, Parkinson TJ and England GCW, 2018. Veterinary Reproduction and Obstetrics, $10^{\text {th }}$ edn., Elsevier, Ltd. Ebook ISBN: 978-0-70207238-3

Roberts SJ, 2004. Veterinary obstetrics and genital diseases. CBS Publishers and distributors, New Delhi, India

Talukdar D, Chutia T, Konwar B, Ahmed FA and Das G, 2016. Management of incomplete uterine inertia in a Labrador bitch - A case report. Int $\mathrm{J}$ Livest Res, 6(9): 79-82, doi: 10.5455/ ijlr.20160901075038

van der Weijden BC and Taverne MAM, 1994. Aspects of obstetric care in the dog. Vet Quart, 16(1): 20-22, doi: 10.1080/01652176.1994.9694467 